\title{
Consolidação do futebol em Belo Horizonte e as conexões de seu meio esportivo (1904-1921)
}

\author{
Football's consolidation in Belo Horizonte and the connections \\ of yours sportive environment (1904-1921)
}

\author{
Raphael Rajão Ribeiro \\ Museu Abílio Barreto (PBH), Belo Horizonte / Brasil \\ Doutorando em História, Política e Bens Culturais, CPDOC-FGV \\ raprajao@gmail.com
}

\begin{abstract}
RESUMO: Assim como nas principais cidades do Brasil, a introdução do futebol em Belo Horizonte se deu de forma independente e seguiu dinâmica própria. Contudo, o meio esportivo local não estava alheio ao que se passava em outras localidades, estabelecendo uma série de conexões ao longo da consolidação dessa prática. 0 presente texto objetiva mapear as articulações promovidas durante esse processo, por meio da circulação de informações, pessoas e mercadorias, nas duas primeiras décadas de desenvolvimento dessa modalidade atlética na capital mineira. Novidades tecnológicas, criação de mercados consumidores, tentativas de institucionalização, intercâmbios de experiências e embates entre diferentes realidades articularam-se num fenômeno inicial de integração regional e nacional que revelava a força dos localismos na composição dos campos esportivos do primeiro quartel do século XX.
\end{abstract}

PalaVRas-CHAVE: Futebol; História do esporte; Circularidade cultural; Culturas urbanas.

ABSTRACT: As well in the Brazilian's most important cities, the introduction of football in Belo Horizonte occurred in an independent way and followed its own dynamic. However, the local sportive environment wasn't unrelated with what was happening in other locations, establishing a series of connections during the consolidation of this practice. The present text aims to map the articulations promoted in this process, through the circulation of information, people and goods during the two first decades of football's development in Minas Gerais' capital city. Technological novelties, creation of consumer markets, institutionalization attempts, exchange of experiences and disputes between different realities were articulated in an initial phenomenon of national and regional integration that displayed localism's force in the composition of the sportive fields in the first quart of the $20^{\text {th }}$ century.

KEYWoRDS: Football; Sport History; Cultural Circularity; Urban Cultures. 


\section{INTRODUÇÃO}

Boa parte da narrativa sobre o futebol brasileiro foi escrita a partir de perspectiva local, que tomou os casos de Rio de Janeiro e São Paulo como medida do todo. Mas seria possível pensar numa influência decisiva desses polos? Qual o grau de articulação dessa prática esportiva em seus anos iniciais? De que forma as histórias do futebol no país se conectaram?

Partindo dessas questões, o presente artigo propõe-se a examinar, com base na trajetória do futebol em Belo Horizonte, as conexões entre a prática dessa modalidade na capital mineira e em outras localidades. Ao perseguir os indícios sobre a circulação de informações, pessoas e mercadorias durante a fase inicial do esporte na cidade, pretende-se indicar algumas das formas de articulação presentes nesse período fundante.

Tais possibilidades foram decorrentes dos avanços tecnológicos que haviam se processado até aquele início de século XX, permitindo que pessoas e mercadorias - e não apenas a informação - pudessem circular com maior facilidade e rapidez. Tal encurtamento das distâncias implicava em ressonâncias diretas no desenvolvimento do futebol na capital mineira. Apesar de bastante ligado a sua realidade regional, seus adeptos viam abertos inúmeros caminhos para o estabelecimento de conexões com o fenômeno mais amplo que se desenrolava especialmente na Europa e na América.

A percepção dessas conexões, não exclui a compreensão de que, tal como defendido pelo geógrafo Gilmar Mascarenhas, o processo de expansão do futebol ocorreu, no caso brasileiro, de forma isolada entre os principais centros urbanos nacionais. Ao seguir o modelo de arquipélago, o autor indica que a introdução da modalidade ligou-se às condições específicas que as diversas cidades reuniam. 0 que explicaria o tempo mais ou menos longo para a consolidação da prática em cada lugar. ${ }^{1}$

No entanto, a constatação de que a dinâmica de difusão do futebol no país esteve vinculada às realidades regionais não tira a importância de experiências externas para casos como o belo-horizontino. Inseridos num momento em que as conexões entre diferentes áreas se ampliavam e atentos ao que se passava no

\footnotetext{
${ }^{1}$ Cf. MASCARENHAS. Futebol e Modernidade no Brasil, p. 2.
} 
Brasil e no mundo, os entusiastas do esporte na capital mineira apropriaram-se de ideias, valores e práticas originárias de variadas localidades, demonstração de que, apesar de seguirem dinâmica própria, eles não se percebiam como isolados de um processo mais amplo.

\section{A IMPORTÂNCIA DAS CONEXõES COM OUTRAS EXPERIÊNCIAS ESPORTIVAS NA DINÂMICA DE IMPLANTAÇÃO DO FUTEBOL EM BELO HORIZONTE}

Belo Horizonte foi construída no final do século XIX para abrigar a capital do estado de Minas Gerais. Já em sua Planta Geral apontava para as articulações com a ciência urbanística europeia, adotando muitas soluções vistas em reformas recentemente realizadas no Velho Mundo. Em seu plano, havia a valorização do esporte como hábito próprio dos modernos centros nacionais e internacionais, com a previsão de um hipódromo e um velódromo, esse último no parque central da então Cidade de Minas.

Foi com base nessas referências que a nova capital vivenciou suas experiências esportivas pioneiras, de ciclismo e hipismo, as quais não tiveram vida longa e sucumbiram ao pouco interesse da população local pelos exercícios atléticos. Mesmo com esse fracasso, a atenção ao que se passava em outros centros permanecia entre parcela dos habitantes de Belo Horizonte, como se verificou no processo de introdução do futebol ali. Se outras modalidades esportivas, como o remo e o turfe, eram relativamente difundidas nos principais centros brasileiros, merecendo, inclusive, colunas nos periódicos da capital federal, ${ }^{2}$ o mesmo não se podia dizer da nova atividade física que chegava à cidade, de implantação recente também no país.

Em 1904, ano de introdução do futebol em Belo Horizonte, somente grandes centros, como o Rio de Janeiro e São Paulo, contavam com bom número de clubes, sendo que, exclusivamente na segunda cidade, realizava-se campeonato regular. ${ }^{3}$ Ainda assim, o novo esporte já era conhecido na capital mineira, como evidenciava crônica que reconstruiu diálogo entre o autor e um amigo, adepto daquela modalidade atlética:

\footnotetext{
${ }^{2}$ Cf. LUCENA. O esporte na cidade.

${ }^{3}$ Cf. PEREIRA. Footballmania; RODRIGUES FILHO. O negro no futebol brasileiro; MAZZONI. História do futebol brasileiro.
} 
- Veja isso. Acabo de receber uma noticia que ia me fazendo perder uma partida de xadrez.

- Que diabo! Que nova foi essa?

- Os paulistas venceram os fluminenses num match de foot-ball. Cinco contra zero!

- Com effeito!

- É esmagador. ${ }^{4}$

Referindo-se a partida realizada entre selecionados daquelas duas cidades, embates que eram disputados desde o início do século, ${ }^{5}$ o entusiasta do futebol indicava estar atento e, até mesmo, envolvido emocionalmente com o jogo, em demonstração de que, ao acompanhar o que se passava com os clubes e as equipes que lhes serviam de inspiração, acabava por assumir a posição de torcedor aficionado.

A ligação com a atividade esportiva desenvolvida em outros lugares foi marcante desde a introdução do futebol na capital mineira, como evidenciou a participação de Victor Serpa que, para além do contato com aquela modalidade atlética durante seus estudos na Suíça, mantinha estreitas relações com o Rio de Janeiro. Carioca de nascença, o jovem acadêmico realizava frequentes viagens para lá. ${ }^{6}$ Aproveitando-se das facilidades criadas por transportes como o trem, comunicava-se com outros praticantes e informava-se acerca daquela prática física no distrito federal.

Da mesma forma, outros integrantes da pioneira agremiação belohorizontina, o Sport Club, a exemplo do comerciante Miguel Liebmann, do dentista Oscar Americano e de J. De Jaegher, frequentemente empreendiam viagens para centros como Rio de Janeiro e São Paulo. ${ }^{7} 0$ que evidenciava as ampliadas possibilidades de estabelecimento de conexões em torno do esporte permitidas pelas facilidades de circulação de pessoas.

O conhecimento acerca do futebol acumulado por Victor Serpa em suas experiências com outros meios atléticos mais bem estruturados, como os da Suíça, do Rio de Janeiro e de São Paulo - localidade que visitou em $1904^{8}$-, garantia a ele

\footnotetext{
${ }^{4}$ OS SARAÓS do Club. A Epocha, 21 ago. 1904, p. 1.

${ }^{5}$ Cf. RODRIGUES FILHO. O negro no futebol brasileiro, p. 34.

${ }^{6}$ Cf. NOTAS. Folha Pequena, 10 ago. 1904, p. 1 e A Epocha, 18 dez. 1904, p. 1.

${ }^{7}$ Cf. HOSPEDES e Viajantes. Minas Geraes, 5 jan. 1904, p. 6; HOSPEDES e Viajantes. Minas Geraes, 23 e 24 jan. 1905, p. 4; HOSPEDES e Viajantes. Minas Geraes, 5 fev.1905, p. 3; HOSPEDES e Viajantes. Minas Geraes, 13 abr. 1905, p. 4; HOSPEDES e Viajantes. Minas Geraes, 21 jun. 1905, p. 4 e HOSPEDES e Viajantes. Minas Geraes, 16 dez. 1905, p. 7.

${ }^{8}$ Cf. HOSPEDES e Viajantes. Minas Geraes, 31 de agosto de 1904, p. 8.
} 
maior prestígio entre seus pares. Cabia a ele, por exemplo, o posto de capitão do Sport Club. Nos seus discursos em defesa da prática esportiva, emergiam referências às experiências que teve fora de Belo Horizonte, como evidenciou representação caricatural publicada na seção humorística de um periódico local, na qual ele foi percebido da seguinte forma:

\author{
Elle fica sem graça e diz muito apressado: \\ 'É preciso educar o povo atrazado!' \\ 'Na Europa - norte a sul - não se encontra um logar \\ Onde o povo não saiba as bolas atirar;' \\ 'E eu vou contar um caso explendido a respeito...' \\ E logo vem um caso intermino e sem geito! \\ Já jogou com Loubet as bolas de manhan, \\ E de tarde fez verso ao lado de Rostand. ${ }^{9}$
}

Afirmando-se como agente de transformação de um meio social atrasado, o sportsman ressaltava o cotidiano dos europeus e a incorporação das práticas atléticas a ele, de modo que, ao mobilizar o imaginário acerca daquele continente como centro da almejada Civilização Ocidental, construía maior legitimidade para o futebol. A utilização do Velho Mundo e, em especial da Inglaterra, como referencial dos adeptos das atividades físicas era evidenciado, dentre outros, pela adoção de vocabulário cheio de estrangeirismos, com termos como goal-keeper, backs, halfs, forwards, match, ground, team e o próprio foot-ball, nas notícias, nos jogos e nos exercícios. Tais palavras, como demonstrou Leonardo Pereira ${ }^{10}$ e como se pôde perceber no caso belo-horizontino, nem sempre eram conhecidas de todos, sendo comuns equívocos nas grafias. Seu domínio era fator de distinção entre quem era ou não iniciado no esporte.

Apesar do vínculo que se procurava estabelecer com o exterior, a difusão do futebol na capital mineira não contou, ao contrário da tendência observada em centros pioneiros, como São Paulo, Rio de Janeiro e Salvador, com a participação da colônia inglesa ou de outros grupos de imigrantes. Ainda que sobrenomes como Liebmann e De Jaegher pudessem ser vistos entre os associados das primeiras

\footnotetext{
${ }^{9}$ FAGULHAS. A Epocha, 16 out. 1904, p. 2.

${ }^{10}$ Cf. PEREIRA. Footballmania, p. 31.
} 
agremiações, ${ }^{11}$ a presença estrangeira era pequena em comparação à grande maioria de brasileiros natos.

Mesmo que a introdução de tal prática atlética tenha sido ação de indivíduos que vivenciavam o futebol fora de Belo Horizonte, outros fatores contribuíram para que os adeptos pudessem conhecê-lo melhor. Recém-criadas tecnologias possibilitavam que as informações circulassem cada vez mais rápido e em maior quantidade. Tal realidade, associada ao incentivo da imprensa local às práticas tidas por modernas, resultava na publicação de artigos que enfocavam as atividades atléticas no Brasil e no mundo.

Tais textos, além de abordar as ações corriqueiras dos clubes esportivos das demais localidades, detinham-se em questões mais complexas, como a disseminação do futebol entre as camadas pobres, a exemplo de passagem acerca do caso paulista:

\footnotetext{
Eu tenho muita pena de vel-as nas suas roupas esfrangalhadas, os olhos lânguidos, as faces pálidas de quem passa má vida, mas ainda sim, na sua innocencia dellas, indifferentes ás miserias terrenas, muito contentes se se lhes depara uma bola de trapos com que começam a fazer exercicios de foot-ball pela poeira negra das ruas. $[\cdots]$

A Varzea do Carmo é o ponto predilecto desses garôtos, que ali passam o dia todo sob a acção rigorosa do sol, quasi sempre jogando o foot-ball. ${ }^{12}$
}

Na crônica, o autor comenta processo que se desenrolava poucos anos após a chegada daquela prática a São Paulo. Ao falar do futebol na Várzea do Carmo, evidencia algo que, por muito tempo, foi ignorado pela memória do futebol construída a posteriori pelos participantes das agremiações mais elegantes, que procuravam valorizar o período em que a atividade permaneceu restrita a eles, estendendo a real duração dessa fase. Tal tipo de notícia, que evidenciava transformações precoces, estava ao alcance dos leitores e podia ser conhecida pelos sportsmen da capital mineira.

O futebol, nesse momento inicial, esteve associado ao universo mais amplo das atividades atléticas, mantendo muitos pontos de contato com outras modalidades. Nessa perspectiva, as matérias veiculadas nos periódicos belo-

\footnotetext{
${ }^{11}$ Cf. FESTAS e Diversões. Minas Geraes, 10 e 11 out. 1904, p. 3.

${ }^{12}$ VIDA Paulista. Minas Geraes, 7 e 8 nov. 1904, p. 4.
} 
horizontinos acerca do tema constituíam objeto de interesse dos adeptos do novo esporte. Tais artigos, que versavam sobre múltiplos assuntos em voga no momento, como questões de saúde e ciência, modelos pedagógicos e desenvolvimento de hábitos modernos, ${ }^{13}$ eram, em boa parte das vezes, traduções ou adaptações de textos retirados de publicações estrangeiras. ${ }^{14}$

Vivendo em uma localidade menor, com população pouco afeita aos divertimentos ao ar livre, os adeptos do futebol em Belo Horizonte procuravam trilhar os caminhos traçados em outras experiências que lhes serviam de modelo. De certa forma, a capital mineira colocava-se como periférica em relação aos grandes centros nacionais, tomados como referencial para seu desenvolvimento.

Apesar de capital do estado e com traçado inspirado nas mais modernas urbs, Belo Horizonte mantinha cotidiano como os dos outros centros mineiros da época. Tal falta de ascendência se expressou, inclusive, no futebol, cuja primazia da introdução coube a Ouro Preto, onde o mesmo Victor Serpa fundou um clube em 1903. ${ }^{15}$

Contudo, o fato de abrigar órgãos da administração pública estadual e instituições de ensino que, apesar de novas, angariavam reconhecimento, garantia a Belo Horizonte a presença de indivíduos com boa condição socioeconômica e com visão cosmopolita, muitos deles originários do interior. Essa situação, somada à difusão de informações sobre a cidade, especialmente pelo jornal de maior circulação de então, o Minas Geraes, órgão oficial do estado, permitia, com o passar do tempo, que a capital mineira se tornasse referência para as localidades próximas, mesmo que timidamente.

Embora não representasse polo difusor do futebol no estado, o meio esportivo de Belo Horizonte, em ocasiões esporádicas, envolveu-se com o desenvolvimento dessa modalidade atlética em cidades do interior. Foi o caso, por exemplo, de Barbacena, que recebeu, em 1905, a equipe do Viserpa Sport Club para

\footnotetext{
${ }^{13}$ São exemplos artigos como A EDUCAÇÃO do caracter. Minas Geraes, 2 fev. 1905, p. 6; EDUCAÇÃO do sangue frio. Minas Geraes, 3 fev. 1905, p. 3; EDUCAÇÃO physica. Minas Geraes, 23 e 24 jan. 1905, p. 3-4 e OS EXERCICIOS physicos e o trabalho mental. Minas Geraes, 24 maio 1905, p. 4.

${ }^{14}$ Evidência que demonstra tal tendência pôde ser verificada em caso que se deu alguns anos depois, em 1913, quando uma mesma matéria foi veiculada sob dois diferentes formatos: primeiramente, em sua língua original e, depois, em versão traduzida para o português. Cf. CAUSERIE medicale. Minas Geraes, 30 abr. 1913, p. 2-3; e PALESTRA Médica. Minas Geraes, 8 maio 1913, p. 2-3.

${ }^{15}$ Cf. Arquivo Privado Abílio Barreto - ABPi 4/029 - O Passado Desportista da Capital.
} 
disputa de partida com o Hugo Braga Football Club, entidade que levava o nome do acadêmico que estudava na mesma faculdade de Direito frequentada por boa parte do time forasteiro. ${ }^{16}$

A estreita relação entre o futuro bacharel e os membros do Viserpa, evidenciava conexões, mesmo que pontuais, com a difusão do futebol no estado. Diferentemente do que acontecia nas partidas mais corriqueiras das equipes belohorizontinas, o jogo realizado em Barbacena foi cercado por inúmeras cerimônias, como relatou $A$ Epocha:

\footnotetext{
Á estação foram recebidos pelos valentes Sportmen barbacenences (sic), sendo erguidos diversos vivas aos dois clubs e ao dr. Henrique Diniz, sendo executadas diversas peças de musica pela excellente banda local.

Como nota mais viva e alegre, achavam-se na estação, formando alas, na porta principal, um grupo de gentis senhoritas.

D'ahi dirigiram-se para o hotel, onde de costume, trocaram-se os cumprimentos de estylo, combinando-se que a partida seria no dia seguinte ás 4 horas da tarde.

Á hora aprasada, chegou ao hotel, em uniforme, o team barbacenense que, incorporado ao do Viserpa, marchou para o ground.

Antes de começar o jogo, fizeram os representantes dos diversos clubs presentes, uma manifestação às moças de Barbacena. ${ }^{17}$
}

O encontro esportivo permeado por atividades antes e depois - quando houve soirré na casa de um morador da cidade - do embate propriamente dito, evidenciava, para além do apreço mútuo, a preocupação dos anfitriões com a construção da imagem de um meio social moderno e elegante. Diferenciando-se de jogos corriqueiros em que havia apenas cumprimentos e breve confraternização ao final, a partida intermunicipal organizada pelo Hugo Braga visava impressionar a comitiva forasteira, a qual, da mesma forma, projetava a representação de componente da parcela mais elegante e moderna de Belo Horizonte. Esses encontros entre os adeptos do futebol das diferentes localidades eram ocasiões para a difusão de imagens acerca do que eles pretendiam ser e de como gostariam de ser vistos.

Mesmo tendo exercido influência no desenvolvimento do futebol em algumas localidades de Minas Gerais, a cidade não se afirmou como polo difusor do esporte.

\footnotetext{
${ }^{16}$ Cf. HOSPEDES e Viajantes. Minas Geraes, 11 jun. 1905, p. 4.

${ }^{17} \mathrm{MATCH}$ de foot-ball. A Epocha, 8 out. 1905, p. 2.
} 
Como evidencia a continuidade da modalidade em localidades como Poços de Caldas e Ouro Preto, ${ }^{18}$ mesmo com o desaparecimento dos clubes pioneiros de Belo Horizonte.

No período em que a atividade das primeiras agremiações se encerrou, críticas por parte da imprensa local destacavam exemplos de localidades como São Paulo que tinha nas modalidades esportivas ferramenta para o desenvolvimento de sua juventude. ${ }^{19}$ De tal forma, mesmo na ausência dos clubes dedicados ao futebol, o olhar para a situação daquela prática pelo país e a circulação de informações se mantiveram.

\section{A CONSTITUIÇÃo dE NOVAS CONEXõES NO RETORNO do FUTEBOl A BELO HORIZONTE}

Se durante a fase inicial do futebol na capital mineira, as experiências de outros locais foram o principal parâmetro para o desenvolvimento da atividade atlética, no momento de retorno da prática regular daquele esporte, tal papel coube à vivência acumulada entre 1904 e 1906. Essa pôde ser resgatada como exemplo próximo e palpável, inclusive, devido à presença de sócios dos clubes pioneiros, como José Gonçalves ${ }^{20}$ e Romulo Joviano, ${ }^{21}$ entre as lideranças na fundação das novas entidades.

Embora Belo Horizonte contasse com o favorecimento da experiência anterior, outros fatores, como a consolidação do futebol em centros do porte de São Paulo, Salvador e Rio de Janeiro, com campeonatos regulares, ${ }^{22}$ não podem ser ignorados como relevantes para o rápido retorno daquele esporte à capital mineira. A considerável presença de notícias sobre eventos atléticos, como se viu na extensa cobertura da partida realizada na capital paulista entre o combinado local e a seleção argentina, em $1908,{ }^{23}$ significava incentivo extra à formação do gosto por tal tipo de divertimento.

\footnotetext{
${ }^{18}$ POÇOS de Caldas. Minas Geraes, 7 jan. 1906, p. 2; DE OURO Preto. A Epocha, 7 jun. 1906, p. 3.

${ }^{19} \mathrm{Cf}$. CHRONICA. Tribuna do Norte, 20 jan. 1907, p. 2.

${ }^{20}$ Cf. FESTAS e Diversões. Minas Geraes, 3 e 4 jan. 1909, p. 6; FESTAS e Diversões. Minas Geraes, 20 maio 1909, p. 6.

${ }^{21}$ Cf. CHRONICA Sportiva. Folha Pequena, 11 out. 1904, p. 1-2; FESTAS e Diversões. Minas Geraes, 31 maio e $1^{\circ}$ jun. de 1909, p. 7.

${ }^{22}$ Cf. MASCARENHAS. Futebol e Modernidade no Brasil, p. 2.

${ }^{23}$ Cf. FESTAS e Diversões. Minas Geraes, 8 jul. 1908, p. 7; FESTAS e Diversões. Minas Geraes, 9 jul. 1908, p. 7.
} 
A publicação de traduções e adaptações de artigos internacionais continuava a garantir que os adeptos do esporte se inteirassem de discussões sobre temas correlatos, como pedagogia e saúde, ${ }^{24}$ da mesma forma que de recentes inovações nas mais variadas modalidades, a exemplo do turfe ${ }^{25}$ e do próprio futebol.

Uma ferramenta tecnológica teve papel central na difusão de dados sobre as atividades atléticas: o telégrafo, que, desde o final do século XIX, era utilizado pela imprensa brasileira. Nos periódicos belo-horizontinos, seu emprego, ao que parece, estava presente desde a chegada do futebol, ainda que a fonte da informação não fosse explicitada. 0 uso se tornou mais evidente, ao final dos anos 1900, com o aparecimento das seções intituladas "telegrammas", de notícias curtas sobre diversas partes do globo, notadamente Europa, Estados Unidos, Argentina e as principais capitais nacionais.

Outras colunas presentes nos periódicos também faziam a circulação de informações sobre eventos esportivos em diferentes localidades. 0 Minas Geraes, por exemplo, veiculava notícias sobre o interior do estado em sua seção Vida Mineira que divulgou provas atléticas em cidades como Juiz de Fora, ${ }^{26}$ Ouro Preto, ${ }^{27}$ Sete Lagoas ${ }^{28}$ e Nova Lima, na época Villa Nova de Lima. ${ }^{29} 0$ mesmo jornal apresentava as Notas do Exterior, que relatavam acontecimentos de variadas modalidades, como o futebol, ${ }^{30}$ o atletismo, ${ }^{31}$ o ciclismo $^{32}$ e a aviação, ${ }^{33}$ em inúmeras partes do globo.

A ampliação da circulação de informações não foi o único caminho para as conexões entre a atividade esportiva da capital mineira e as de outras localidades. Várias foram as ocasiões em que os atletas da cidade encontraram-se com seus

${ }^{24}$ Cf. A MISSÃO do magisterio. Minas Geraes, $1^{\circ}$ fev. 1908, p. 3-4; EDUCAÇÃO da voz. Minas Geraes, $1^{\circ}$ out. 1908 , p. 5.

${ }^{25}$ SPORT. Minas Geraes, 23 out. 1908, p. 6-7.

${ }^{26}$ Cf. VIDA Mineira. Minas Geraes, 17 jul. 1908, p. 6; VIDA Mineira. Minas Geraes, 1ํ maio 1909, p. 5.

${ }^{27}$ Cf. VIDA Mineira. Minas Geraes, 14 ago. 1908, p. 6; VIDA Mineira. Minas Geraes, 29 ago. 1908, p. 7.

${ }^{28}$ Cf. VIDA Mineira. Minas Geraes, 7 e 8 jun. 1909, p. 6.

${ }^{29}$ Cf. VIDA Mineira. Minas Geraes, 14 jan. 1910, p. 6.

${ }^{30}$ Cf. NOTAS do Exterior. Minas Geraes, 21 abr. 1909, p. 5; NOTAS do Exterior. Minas Geraes, 10 jun. 1909 , p. 6.

${ }^{31}$ Cf. NOTAS do Exterior. Minas Geraes, 19 mar. 1909, p. 5.

${ }^{32}$ Cf. NOTAS do Exterior. Minas Geraes, 8 jul. 1909, p. 7.

${ }^{33}$ Cf. NOTAS do Exterior. Minas Geraes, 2 jun. 1909, p. 6; NOTAS do Exterior. Minas Geraes, 13 nov. 1909 , p. 7. 
congêneres vindos de lugares diversos. 0 Yale Athletic Club foi uma entidade particularmente pródiga em promover tais encontros no início da década de 1910.

Apesar de a trajetória inicial do futebol belo-horizontino não ter contado com participação intensa de imigrantes, a poucos quilômetros da cidade, Morro Velho, um núcleo de ingleses, criado no município de Nova Lima em função da exploração de jazidas minerais a cargo de empresa britânica, era sede da, então considerada, melhor equipe da modalidade em Minas Gerais. Ali, o esporte era particularmente apreciado, verificando-se a realização de disputas variadas, todas no âmbito do Morro Velho Athletic Club, como evidenciaram reportagens publicadas no Minas Geraes em 1911. ${ }^{34}$

Mesmo com a proximidade geográfica, não ocorriam partidas contra agremiações da capital. Porém, em 1911, o Yale alterou tal situação e foi a Morro Velho para jogo que despertou interesse da imprensa. Os comentários sobre o desenrolar do certame revelaram percepções divergentes da modalidade e da forma como praticá-la:

0 jogo foi encarniçado de parte a parte, tendo os inglezes atacado, desde o principio, terrivelmente o gool (sic), porém sem resultado.

Esse ardor foi arrefecendo ante a attitude do 'Yale', leal e honesto sempre em sua defesa.

Afinal, depois dos mais emocionantes transes e exgottado o tempo, verificou-se o empate, sem ser cortado ponto algum a ambos os Clubs.

Convem notar que os inglezes nem sempre foram leaes em sua acção, recorrendo a passes condemnados, tendo a seu lado, com irritante parcialidade, o refree (sic), o que foi geral e desagradavelmente commentado pela assistencia numerosa. ${ }^{35}$

Conforme evidencia a citação, dois estilos de jogo se opuseram naquele encontro. Enquanto os jovens da capital prendiam-se a uma postura mais cavalheiresca, atentos aos preceitos do fair play, os atletas ingleses demonstravamse mais apegados à competitividade, com uso da força física. Os sócios do Yale, que alcançaram o empate contra os renomados futebolistas, puderam, com essa partida intermunicipal, testar de maneira mais intensa suas estratégias, assim como conhecer novas perspectivas táticas. Além do aspecto da integração entre

\footnotetext{
${ }^{34}$ Cf. MORRO Velho. Minas Geraes, 5 jul. 1911, p. 3-4; MORRO Velho. Minas Geraes, 13 jul.1911, p. 3; MORRO Velho. Minas Geraes, 30 jul. 1911, p. 12.

35 "YAIE" (sic) versus "Morro Velho", O Estado, 2 ago. 1911, p. 2.
} 
grupos que compartilhavam o gosto pelo esporte, tais eventos ofereciam chance de aprimoramento técnico. Ao enfrentar adversários superiores, os belo-horizontinos desenvolviam seus conhecimentos e habilidades.

Oportunidade ainda mais interessante se deu naquele mesmo ano de 1911, com o segundo jogo interestadual da cidade, ${ }^{36}$ quando o America do Rio de Janeiro, campeão carioca daquela temporada, veio a Belo Horizonte para disputar partida com o Yale. A visita da afamada agremiação da capital federal foi cercada de solenidades e de entusiasmo, com recepção no Salão de Honra do Palácio Presidencial do Estado, desfile em bonde especial com banda de música e banquete no Grande Hotel, ${ }^{37}$ atitude bastante similar à observada durante a estada do Viserpa em Barbacena, seis anos antes.

As conexões estabelecidas pelo futebol de Belo Horizonte não se restringiram ao trânsito de pessoas e à difusão de informações. Para além disso, observou-se a circulação de mercadorias, presente desde a introdução da modalidade. Episódio ilustrativo do fenômeno se deu no momento de retorno das agremiações do gênero à cidade, na formação do, então chamado, Athletico Mineiro Football Club. Preparando-se para o início dos treinos, seus jovens membros se viram sem o material esportivo necessário. Conforme relato publicado, anos depois, no jornal Estado de Minas:

[...] A primeira sede foi um cantinho do porão da casa onde residia Vate (Marginal Leal), à rua Goiaz, nos fundos do Palacio da Justiça, onde foram discutidos os problemas, para que o clube tomasse impulso.

Mas, antes, os garotos tiveram que vencer o problema mais sério para enfrentar a realidade - a bola. Naquele tempo, Ninico Antunes (hoje dr. Antonio Antunes Filho) enviava besouros e outros 'bchinhos'(sic) para um amigo que residia na França, que o creditava da importancia das despesas feitas. Ai estava a solução do problema sério - Ninico Antunes pediria ao amigo que lhe enviasse uma bola, em troca do que lhe devia. E isso foi feito. A pelota chegou, para alegria dos garotos atleticanos uma bola numero 3 , que custara naquela epoca a apreciavel soma de 11 cruzeiros. $^{38}$

\footnotetext{
${ }^{36}$ O primeiro foi entre o Riachuelo F. C., do Rio de Janeiro, e o Sport Club, jogo disputado no Parque Municipal. Cf. FESTAS e Diversões. Minas Geraes, 12 e 13 set. 1910, p. 6.

${ }^{37}$ Cf. FESTAS e Diversões. Minas Geraes, 17 nov. 1911, p. 7; MATCH de Foot-ball. O Estado, 17 nov. 1911; MATCH de Foot-ball. Estado de Minas, 18 nov. 1911, p. 2.

${ }^{38}$ A PRIMEIRA bola veio da França. Estado de Minas, 31 dez. 1949, p. 8. Apud Arquivo Privado Abílio Barreto - ABPi 7/061.
} 
Em 1908, a circulação dos materiais destinados à prática do futebol ainda era escassa, a exemplo do que se via, poucos anos antes, com clubes cariocas, como o Botafogo, que compravam diretamente da Inglaterra os equipamentos necessários. ${ }^{39}$ Numa época em que aquela modalidade era restrita, a importação por encomenda era a principal forma de se adquirir tais mercadorias. Episódios, como o do Athletico, evidenciavam a ligação entre o esporte e o desenvolvimento de novos hábitos de consumo próprios da expansão do capitalismo, sendo a adesão ao recémimplantado divertimento impulso para a constituição de novos mercados locais.

O crescimento da atividade futebolística na capital mineira implicava na expansão da necessidade por materiais esportivos, fato que era percebido pelos comerciantes da cidade, que começavam a ver os atletas como consumidores em potencial. No processo de formação desse novo mercado local, eventos, como o jogo interestadual entre o America do Rio de Janeiro e o Yale, constituíam-se em ocasião para a divulgação dos produtos, como se viu no seguinte anúncio veiculado em $O$ Estado:

\author{
Sortimento chegado ultimamente para a \\ Bota Americana \\ Chapéos chile e Panamá; lindos guarda-chuvas para homens e senhoras \\ Artigos para Foot Ball \\ Chapeós borsalino em todas as fôrmas, e grande sortimento de calçado para \\ creanças; novas marcas de calçados Melillo para homens e senhoras. \\ A maior modicidade em preços \\ AVENIDA AFONSO PENNA, 739. ${ }^{40}$
}

Mesmo sem especificar quais itens oferecia, falando apenas em "Artigos para Foot Ball”, o anúncio evidenciava a afirmação de público numeroso o suficiente para motivar a encomenda antecipada, sem pedidos prévios. Incentivos à expansão desse mercado eram criados pelo governo federal com a edição da Lei n. 3.446, de 31 de dezembro de 1917 que isentava de taxas alfandegárias o material esportivo importado. ${ }^{41}$

Um produto que representava tanto a circulação de mercadorias como a de informação constituía-se nos guias esportivos, gênero de literatura que começou a ser editado no Brasil, ainda no século XIX, sendo voltado, inicialmente, para a

\footnotetext{
${ }^{39}$ Cf. PEREIRA. Footballmania, p. 39.

${ }^{40}$ O Estado, 16 nov. 1911 , p. 4.

${ }^{41}$ LEGISLAÇÃO Federal. Minas Geraes, 16 jan. 1918, p. 1-4.
} 
ginástica e outras atividades físicas. Em 1913, momento no qual o futebol já se consolidava na cidade, ganhando inclusive maior espaço na mídia impressa, o jornal Estado de Minas lançou sua Secção Sportiva que, em suas primeiras aparições, informava ter recebido:

[...] enviado pela Casa Narciso, desta capital, um exemplar do Guia Sportivo, trazendo informações completas sobre os mais conhecidos jogos ao ar livre, como sejam o Foot-ball e Lawn-Tennis.

A título de propaganda do sport, vamos transcrever a introducção assignada por Mario Cardin, com o titulo 'Um pouco de historia... de football' ${ }^{42}$

Não se sabe ao certo se, anteriormente, outras edições similares ao Guia Sportivo foram comercializadas na cidade. Porém, a oferta de tal obra, cujo conteúdo englobava dados variados sobre o futebol e o tênis, inclusive as regras das modalidades, representava oportunidade de fácil acesso ao saber qualificado sobre o esporte.

Outro veículo para constituição de conexões foram escolas como, por exemplo, o Gymnasio Anglo-Mineiro. Ao adotar o modelo inglês de ensino, a instituição implementou o uso pedagógico de inúmeras modalidades, como o futebol. Para tanto, contou, entre seus professores, com vários britânicos, ${ }^{43}$ destacados jogadores, que logo encontraram espaço nas equipes locais, tornandose difusores de técnicas diversas.

O crescimento do futebol na capital mineira impunha a seus adeptos a necessidade de consolidar uma organização mais ampla das agremiações da cidade. Tal grupo, atento a toda a circulação de informações e às conexões estabelecidas pelo meio esportivo local, buscava, em experiências atléticas que haviam se desenvolvido em outros lugares, parâmetros para a efetivação das transformações que se tornavam prementes. Dessa forma, a aproximação entre a criação das entidades dirigentes e dos campeonatos de Belo Horizonte com os de outros centros nacionais pôde ser observada.

\footnotetext{
42 SECÇÃO Sportiva. Estado de Minas, 8 jun. 1913, p. 2-3.

${ }^{43}$ Cf. Minas Geraes, 21 set. 1913, p. 8; RODRIGUES. Constituição e enraizamento do esporte na cidade, p. 213-221.
} 


\section{DESENVOLVIMENTO E LIMITES DA INTEGRAÇÃO INSTITUCIONAL REGIONAL E NACIONAL DURANTE A CONSOLIDAÇÃO DO CAMPO ESPORTIVO EM BELO HORIZONTE}

A organização de torneios como a Taça Bueno Brandão, em $1914,{ }^{44}$ era indicativo de que, dentro do desejo de se criar critérios mais claros para definição de qual era a melhor equipe esportiva da cidade, os atletas e os dirigentes belo-horizontinos mostravam-se atentos a experiências desenvolvidas em centros como São Paulo, onde a competição promovida pela Liga Paulista já passava de sua décima edição. Como parte do movimento de elaboração de instituições futebolísticas, os membros dos clubes da capital mineira fundaram, no ano seguinte, a Liga Mineira de Sports Athleticos (LMSA). ${ }^{45}$

Depois de uma década, Belo Horizonte voltava a contar com entidade dirigente do esporte, já que tivera, em 1904, liga de curta existência. ${ }^{46}$ Se a nova associação, por um lado, apontava para o retorno de tendência já vista na cidade, por outro, evidenciava a referência a experiências dos centros nacionais, conforme demonstrou o nome similar ao da congênere carioca, Liga Metropolitana de Sports Atleticos. ${ }^{47}$

Tal como sugere o nome da instituição, para além de pretender gerir ampla variedade de modalidades, almejava-se fazê-lo em nível estadual, o que esbarrava na falta de integração das diversas áreas de Minas e de capacidade da capital de afirmar-se como polo regional. A implantação do campeonato constituiu um calendário futebolístico no qual várias datas ficaram reservadas para jogos que, majoritariamente, envolviam equipes do interior, promovendo, ainda que precariamente, o intercâmbio com os atletas dessas localidades. A realização desses certames como amistosos, mesmo em casos de cidades próximas, ${ }^{48}$ indicava, contudo, os limites da atuação da LMSA.

Enquanto a integração da entidade mineira com as localidades do estado era, em meados da década de 1910, muito tímida, instituições atléticas nacionais buscavam aproximação com organismos e agremiações internacionais. Visando

\footnotetext{
${ }^{44}$ Cf. FESTAS e diversões. Minas Geraes, 8 jul. 1914, p. 10; FESTAS e diversões. Minas Geraes, 12 jul. 1914, p. 13; e FESTAS e diversões. Minas Geraes, 20 e 21 jul. 1914, p. 10.

${ }^{45}$ Cf. SPORT. Vida de Minas, 15 fev. 1915, p. 56.

${ }^{46}$ Cf. FESTAS e Diversões. Minas Geraes, 26 out. 1904, p. 7.

${ }^{47}$ Cf. PEREIRA. Footballmania, p. 65.

${ }^{48}$ Cf. FESTAS e diversões. Minas Geraes, 24 out. 1915, p. 13; e FESTAS e diversões. Minas Geraes, 29 out. 1915 , p. 5.
} 
criar associação que tivesse representatividade frente a Federação Internacional de Futebol Association (FIFA), principal responsável pelo futebol mundial, paulistas e cariocas, não sem antes resolver impasses envolvendo oposições de interesses, criaram, em 1916, a Confederação Brasileira de Desportos (CBD). ${ }^{49}$

Parte do projeto daqueles dois centros era coordenar o desenvolvimento das atividades atléticas brasileiras. Sua atuação de forma mais ativa, em Belo Horizonte, pôde ser sentida, pela primeira vez, no final do ano seguinte à sua fundação. Na ocasião, houve intervenção da CBD para a solução da cisão que atingia a LMSA e o meio esportivo local. Tal querela se originou durante os preparativos para o jogo interestadual entre o America e o Clube de Regatas Flamengo, quanto teria ocorrido confrontação à autoridade do presidente da associação mineira, conforme informou o Minas Geraes:

Afim de resolver a dualidade de presidencia que á Confederação de Desportos se afigurou existir na directoria da Liga Mineira de Sports Athleticos, foram a Belo Horizonte, afim de estudar o caso e propor solução para elle, os srs. Marcondes Ferraz e Heitor Luz, ambos representantes da Liga Mineira junto á Confederação de Desportos.

Esta providencia inspirada pelo esforço do dr. Arnaldo Guinle, resultou no mais legitimo successo. ${ }^{50}$

Uma integração institucional começava a se constituir. A partir daí, foram criados alguns vínculos entre a associação estadual - que foi rebatizada, a exemplo do que havia acontecido com sua congênere carioca, de Liga Mineira de Desportes Terrestres (LMDT) ${ }^{51}$ - e sua instância superior. Da mesma forma foi promovido, em certa medida, o fortalecimento das conexões do meio atlético local com o dos grandes centros brasileiros. Relação que não se estabeleceu num quadro de igualdade de forças, com menor representatividade mineira em comparação a paulistas e cariocas.

A tendência ao início da integração pôde ser notada também na esfera regional. A antiga LMSA, transformada em LMDT, começava a se tornar influente em outras localidades, aumentando o número de afiliados e atingindo regiões mais

\footnotetext{
${ }^{49}$ Cf. CALDAS. O Pontapé Inicial, p. 39.

${ }^{50}$ FESTAS e diversões. Minas Geraes, 5 set. 1917, p. 7.

${ }^{51}$ Cf. SECÇÃO Alheia. Minas Geraes, 5 set. 1917, p. 7-8.
} 
distantes. Foi o caso de Juiz de Fora, onde ela estabeleceu a sub-liga, ${ }^{52}$ demonstração tanto da força do cenário atlético daquela cidade da Zona da Mata, quanto dos limites da atuação da entidade estadual. Ao assumir papel mais ativo na coordenação do esporte mineiro e contar com os principais clubes de importantes centros em seus quadros, a liga era procurada por cada vez mais agremiações, como evidenciou o seguinte anúncio:

Por estes dias o Lavras Sport Club pedirá sua filiação á Liga Mineira. Depois de filiado a valorosa aggremiação Sportiva de Lavras, que conta no seu seio com a élite da mocidade de Lavras, proporá ao America F. B. C. um match. ${ }^{53}$

Num momento em que o campeonato da instituição ainda se mantinha restrito às proximidades da capital, as associações de cidades mais afastadas tinham oportunidade de enfrentar os melhores conjuntos apenas em partidas isoladas. A constituição de ligas implicava também na formação, com maior frequência, de selecionados locais, sendo que o combinado belo-horizontino passou a travar jogos regularmente com equipes cariocas e juizforanas. ${ }^{54} \mathrm{~A}$ circulação de textos nos jornais locais em defesa da superioridade do meio atlético de cada centro era grande, acirrando rivalidades. ${ }^{55}$

Paralelamente ao processo de aproximação institucional que representava ainda tímido movimento de integração regional e nacional, a tendência de vinculação de novos significados ao futebol, com a incorporação de ideias que ganharam força ao longo da década de 1910, podia ser percebida nos principais centros brasileiros e, em alguns casos, mundiais. Foi o caso, por exemplo, da associação do esporte com o discurso nacionalista que emergia no Brasil, ainda que não constituísse ideologia de governo, como se veria vinte anos depois.

Entre os principais entusiastas desse discurso estava o poeta Olavo Bilac, cuja visita a Belo Horizonte, em 1916, movimentou diversos setores da cidade, ansiosos

\footnotetext{
${ }^{52}$ Cf. SECÇÃO Sportiva. Novidades, 13 fev. 1919, p. 2.

${ }^{53}$ SECÇÃO Sportiva. Estado de Minas, 23 ago. 1919, p. 3. Segundo regulamento da LMDT, apenas equipes filiadas podiam realizar jogos contra os clubes já pertencentes aos seus quadros, inclusive com risco de punição aos que descumprissem a orientação. Cf. SECÇÃO Sportiva. Estado de Minas, 8 nov. 1919, p. 3.

${ }^{54}$ Cf. SECÇÃO Sportiva. Estado de Minas, 12 ago. 1919, p. 3; SECÇÃO Sportiva. Estado de Minas, 15 set. 1919, p. 3; FESTAS e diversões. Minas Geraes, 12 out. 1919, p. 6; SPORTS. Estado de Minas, 7 set. 1920, p. 3; e FESTAS e Diversões. Minas Geraes, 25 mar. 1921, p. 8. ${ }^{55}$ Cf. SPORTS. Estado de Minas, 7 set. 1920, p. 3.
} 
por travar contato com o intelectual. Temas como as atividades ginásticas e o esporte estiveram presentes na série de compromissos que teve e nas palestras que proferiu. ${ }^{56}$

A presença do reconhecido difusor do pensamento nacionalista aplicado às práticas atléticas não significava propriamente oportunidade dos adeptos do futebol local conhecerem suas ideias, as quais provavelmente já haviam descoberto antes. Contudo, a visita de Olavo Bilac chamava a atenção de público maior para o tema, auxiliando na divulgação de valores para a legitimação do esporte na cidade.

Debates sobre novidades como a teoria eugênica que começava a ser adotada, particularmente, nos meios médicos, ${ }^{57}$ apareciam nas páginas dos periódicos do final da década de 1910 e se articulavam com discussões sobre a prática esportiva. ${ }^{58}$

A adoção das atividades atléticas pelas classes populares foi fenômeno que não se restringiu a Belo Horizonte, tendo ocorrido em importantes centros nacionais. Esse processo de disseminação, que atingiu particularmente o futebol, era bastante divulgado nas notícias que circulavam na imprensa da capital mineira, de modo que os atletas locais, por meio delas e dos contatos que travavam com seus pares de diversas cidades, mantinham-se informados das mudanças por que passava tal ramo dos divertimentos.

Clubes como o Yale, que cultivavam forte ligação com sua condição social e com sua vizinhança, buscavam estabelecer conexões com entidades futebolísticas que possuíssem perfil similar, conforme evidenciou Leonardo Pereira na seguinte passagem:

[...] Grêmios proletários de outros estados como o Yale Atletic Club, de Belo Horizonte, chegavam a buscar nos sócios de clubes como o Bangu um apoio que tinha no perfil de seus associados sua maior justificativa. 'Formado de operários', ele pedia 'auxílio para a construção de um pavilhão em seu ground', contando com uma ajuda que tinha na identificação entre os sócios dos dois clubes sua única base. ${ }^{59}$

\footnotetext{
${ }^{56}$ Cf. OLAVO Bilac. Minas Geraes, 26 ago. 1916, p. 5-6; OLAVO Bilac. Minas Geraes, 27 ago. 1916, p. 9-11; OLAVO Bilac. Minas Geraes, 28 e 29 ago. 1916, p. 5-6.

${ }^{57}$ Cf. Minas Geraes, 27 abr. 1913, p. 8; EUGENIA brasileira. O Commercio de Minas, 13 maio 1916, p. 2.

58 "RADIUM" Desportivo. Radium, set. de 1920, p. 31.

${ }^{59}$ PEREIRA. Footballmania, p. 273.
} 
Percebendo semelhança com a agremiação carioca, os membros do Yale procuravam, a partir da identificação mútua, conseguir ajuda para a implantação da melhoria em seu campo de jogo. Importante referencial de associação esportiva de fábrica, o Bangu era visto, ao mesmo tempo, como par e possível patrono.

Outro tipo de identidade que surgiu com destaque no meio esportivo da capital mineira foi a imigrante. Se, ao contrário de outros centros, o futebol em Belo Horizonte não contou com a presença de estrangeiros, principalmente ingleses, em seu processo de implantação, no final da década de 1910, agremiações fundadas no seio de colônias mais pobres, como os portugueses e os italianos, começaram a se fazer presentes.

Entre os italianos de Belo Horizonte, que buscavam, em meio à colônia não muito coesa, formar um clube de futebol, exemplos vindos de outros centros, como no caso do Palestra de São Paulo, serviam de parâmetro e estímulo para a entidade que vieram a fundar, em 1921, com o nome de Società Sportiva Palestra Italia. ${ }^{60}$

0 futebol era um dos ramos mais bem sucedidos dos divertimentos da capital mineira. Ao seu lado, contudo, outro tipo de entretenimento alcançou grande notoriedade na cidade: o cinema. Entre essas duas práticas sociais modernas, não só o bom acolhimento do público constituía ponto de contato. Por diversas vezes, o primeiro ganhou as telas do segundo, sendo tema recorrente de inúmeras películas.

0 cinema sempre se mostrava atento às últimas novidades mundiais, buscando oferecer aos seus espectadores imagens que chamassem a atenção, seja pelo exotismo, pelo humor, pela imponência ou pela dramaticidade. Assim, não foi de se estranhar que, ainda em seus primórdios, as atividades atléticas constituíssem um dos seus objetos de interesse. Películas como "Sport em Botavia", "Exercicio de natação", "Páreos internacionaes de Skis", "Sports no Voges”, "Sport no Egypto" e "Sport invernal", classificadas como "naturais", 61 algo que se

\footnotetext{
${ }^{60}$ Cf. SANTANA. Páginas Heróicas, p. 27-31.

${ }^{61}$ FESTAS e Diversões. Minas Geraes, 13 jun. 1909, p. 6; FESTAS e diversões. Minas Geraes, $1^{\circ}$ jan. 1910, p. 6; FESTAS e diversões. Minas Geraes, 7 maio 1910, p. 7; FESTAS e diversões. Minas Geraes, 12 maio 1910, p. 7; PELOS Cinemas. Estado de Minas, 11 out. 1912, p. 2; DIVERSÕES Varias. Estado de Minas, 8 jun. 1913, p. 2. Filmes humorísticos como "Sport da moda", "Max exercita-se no ski" e "Did Sportsman" também eram exibidos nos cinemas belo-
} 
aproximaria do gênero atual do documentário, eram algumas, dentre as várias exibidas na capital mineira.

Outro gênero que fazia a divulgação de fatos, especialmente relativos à Europa, era o dos cinejornais, com temas variados, como destacou o anúncio do “'Gaumont Jornal', numero XXVI sobre modas, actualidades mundiaes, novidades semanes e sportivas". ${ }^{62}$ Tais noticiários cinematográficos foram exibidos com frequência regular ao longo de toda a década de 1910. Películas semelhantes acerca do Brasil também circulavam, ${ }^{63}$ apesar de não manterem a mesma continuidade.

A fotografia que, na época, era pouco veiculada em jornais, sendo difundida, principalmente, através das revistas, foi, assim como o cinema, outro importante meio imagético de difusão de informações acerca do esporte. Era comum a inserção de imagens do movimento atlético nas localidades do interior. ${ }^{64}$ Assim como no caso de Belo Horizonte, essas iconografias voltavam mais seu olhar para o público assistente. $^{65}$

No contexto de desenvolvimento das atividades atléticas no Brasil e de tentativas de aproximação entre seus principais centros urbanos, esses dois mecanismos de circulação da informação desempenharam papel importante na divulgação de eventos que estiveram diretamente ligados às transformações por que o esporte passava. No final da década de 1910, a filmagem e a exibição de jogos de futebol nos cinemas já era comum, inclusive em Belo Horizonte. ${ }^{66}$ Apesar de não se constituir mais em novidade, uma série de películas despertou o interesse dos espectadores da capital mineira: as referentes ao Sul-Americano de 1919, realizado no Rio de Janeiro.

Tal competição que, na visão de muitos estudiosos, foi momento chave da construção do sentimento nacionalista em torno do futebol, ${ }^{67}$ recebeu pouca atenção dos periódicos belo-horizontinos. Essas folhas, apesar de divulgarem seu

horizontinos. Cf. FESTAS e diversões. Minas Geraes, 29 maio 1910, p. 5; FESTAS e diversões. Minas Geraes, 7 jul. 1910, p. 8; DIVERSÕES Varias. Estado de Minas, 12 jun. 1913, p. 3.

${ }^{62}$ FESTAS e Diversões. Minas Geraes, 14 ago. 1912, p. 6.

${ }^{63}$ Cf. FESTAS e Diversões. Minas Geraes, 26 jul. 1912, p. 3.

${ }^{64}$ Cf. VITA em Ouro Preto. Vita, 15 fev. 1914, p. 21; NOTAS Sportivas. Vita, 26 jun. 1914, p. 15.

${ }^{65}$ Cf. "TANK" em S. João D'el Rey. Tank, out. 1920, p. 14.

${ }^{66}$ Cf. FESTAS e diversões. Minas Geraes, 28 jul. 1918, p. 6.

${ }^{67}$ Cf. FRANZINI. As Raízes do País do Futebol; PEREIRA. Footballmania; RODRIGUES FILHO. O negro no futebol brasileiro. 
desenrolar, ${ }^{68}$ mostravam-se mais interessadas na promoção do Torneio das Rosas, entre os clubes da cidade, em celebração ao Dia da Boa Imprensa. ${ }^{69}$ Em meio aos torcedores da cidade, a disputa internacional também pareceu não ser alvo de muito entusiasmo, especialmente se comparado ao comportamento dos cariocas, que lotaram o estádio durante as partidas e as ruas em suas comemorações. ${ }^{70}$

Se o desenrolar do torneio continental não despertou interesse em Belo Horizonte, o mesmo não pode ser dito sobre a exibição dos filmes daqueles jogos que, pelo grande número de sessões, atraiu bom público. ${ }^{71}$ Tal dissonância entre as atenções dispensadas ao evento e aos seus registros visuais se explicava pelo fato de que os espectadores dessas películas compunham-se de torcedores curiosos em ver a forma como a modalidade era praticada na América do Sul e de adeptos do futebol preocupados em conhecer técnicas e táticas de jogo. Ao que parece, não havia entusiastas do que era entendido, naquele momento, como o selecionado brasileiro. A construção da identidade nacional vinculada ao esporte dava mostras de ainda estar longe de atingir a capital mineira, pouco integrada ao centro decisório do país.

$\mathrm{Na}$ passagem da década de 1910 para a de 1920, observava-se que o processo de aproximação institucional, com vistas à integração, tanto nacional quanto regional, ainda vivenciava seu momento inicial. A CBD, que havia dado mostras de que se envolveria mais diretamente com o meio esportivo belohorizontino e mineiro ao intervir na antiga LMSA e transformá-la em LMDT, manteve-se distante. Indicativos de fortalecimento dos laços entre as capitais estadual e federal eram dados apenas pela frequência cada vez maior de jogos entre equipes e selecionados das duas localidades.

Da mesma forma, as ações da LMDT mostraram-se bastante restritas até o início dos anos 1920. Sem dúvida, um princípio de integração regional já podia ser visto na época. Contudo, a maior participação dos clubes do interior era algo que iria se constituir no futuro, pois apenas agremiações das proximidades de Belo

\footnotetext{
${ }^{68}$ Cf. TELEGRAMMAS. Minas Geraes, 24 maio 1919, p. 6; e Minas Geraes, 1ำ jun. 1919, p. 5.

${ }^{69}$ Cf. DIA da Bôa Imprensa. Minas Geraes, 29 maio 1919, p. 3; DIA da Bôa Imprensa. Minas Geraes, 29 maio 1919, p. 3-4.

${ }^{70}$ Cf. PEREIRA. Footballmania, p. 148-154.

71 Cf. ANNUNCIOS. Minas Geraes, 13 jun. 1919, p. 8; ANNUNCIOS. Minas Geraes, 14 jun. 1919, p. 16; ANNUNCIOS. Minas Geraes, 15 jun. 1919, p. 16; ANNUNCIOS. Minas Geraes, 17 jun. 1919, p. 8; e ANNUNCIOS. Minas Geraes, 19 jun. 1919, p. 8.
} 
Horizonte participavam nos campeonatos organizados pela entidade dirigente do futebol estadual.

Para além do aspecto institucional, a capital mineira ainda se colocava na condição de centro periférico do futebol nacional. Mesmo depois de mais de quinze anos da introdução de tal modalidade na cidade, o desequilíbrio entre as relações que o meio atlético local estabelecia com outros lugares era perceptível, sendo que a maior transformação era o crescimento substancial das conexões, fornecendo maiores subsídios para as ações dos esportistas belo-horizontinos.

Os projetos de construção da identidade nacional e da integração esportiva não tiveram efeito na cidade até o início da década de 20. Apesar de esboçarem alguma estruturação em lugares como o Rio de Janeiro, elas pouca reação provocavam na população e nas agremiações locais. Os grandes centros nacionais não eram vistos como parte do mesmo movimento atlético, a percepção de uma unidade ainda se restringia a Belo Horizonte, para fora dali, o que se via eram outras realidades, outros contextos.

\section{REFERÊNCIAS}

"RADIUM" Desportivo. Radium, Belo Horizonte, set. de 1920, p. 31.

“TANK” em S. João D’el Rey. Tank, Belo Horizonte, out. 1920, p. 14.

A Epocha, Bello Horizonte, 1904-1906. [Seleção].

CALDAS, Waldenyr. O pontapé inicial: memória do futebol brasileiro (18941933). São Paulo: IBRASA, 1990.

CHRONICA. Tribuna do Norte, Belo Horizonte, 20 jan. 1907, p. 2.

COUTO, Euclides de Freitas. Belo Horizonte e o futebol: integração social e identidades coletivas (1897-1927). 2003. Dissertação (Mestrado) - PUC, Belo Horizonte, 2003.

Estado de Minas, Belo Horizonte, 1911-1913. [Seleção].

Estado de Minas, Belo Horizonte, 1919-1920. [Seleção].

EUGENIA brasileira. O Commercio de Minas, Belo Horizonte, 13 maio 1916, p. 2.

Folha Pequena, Belo Horizonte, 1904. [Seleção].

FRANZINI, Fábio. As raízes do país do futebol: Estudo sobre a relação entre o futebol e a nacionalidade brasileira (1919-1950). 2000. Dissertação (Mestrado) - FFLCH - USP, São Paulo, 2000. 
LUCENA, Ricardo de Figueiredo. O esporte na cidade: aspectos do esforço civilizador brasileiro. Campinas, SP: Autores Associados, 2001.

MASCARENHAS, Gilmar. Futebol e Modernidade no Brasil: A geografia histórica de uma inovação. Lecturas: Educación Física y Deportes [online], mayo 1998, año 3, n. 10. Disponível em: <goo.gl/N69VP1>. Acesso em: 18 out. 2017.

MAZZONI, Thomaz. História do futebol brasileiro. São Paulo: Leia, 1950.

Minas Geraes, Belo Horizonte, 1904-1906; 1908-1919; 1921. [Seleção].

O Estado, Belo Horizonte, 1911. [Seleção].

PEREIRA, Leonardo Affonso de Miranda. Footballmania: uma história social do futebol no Rio de Janeiro, 1902-1938. Rio de Janeiro: Nova Fronteira, 2000.

RODRIGUES, Marilita Aparecida Arantes. Constituição e enraizamento do esporte na cidade - uma prática moderna de lazer na cultura urbana de Belo Horizonte (1894-1920). 2006. Tese (Doutorado) - UFMG, Belo Horizonte, 2006.

RODRIGUES FILHO, Mário. O negro no futebol brasileiro. Rio de Janeiro: Mauad, 2003.

SANTANA, Jorge. Páginas heróicas: onde a imagem do Cruzeiro resplandece. São Paulo: DBA, 2003.

SECÇÃO Sportiva. Novidades, Belo Horizonte, 13 fev. 1919, p. 2.

SPORT. Vida de Minas, Belo Horizonte, 15 fev. 1915, p. 56.

Vita, Belo Horizonte, 1914. [Seleção]. 